This is the final peer-reviewed accepted manuscript of:

Ciabocco, M., Cancemi, P., Saladino, M.L. et al. Synthesis and antibacterial activity of iron-hexacyanocobaltate nanoparticles. J Biol Inorg Chem 23, 385-398 (2018).

The final published version is available online at https://doi.org/10.1007/s00775018-1544-x

Rights / License:

The terms and conditions for the reuse of this version of the manuscript are specified in the publishing policy. For all terms of use and more information see the publisher's website.

This item was downloaded from IRIS Università di Bologna (https://cris.unibo.it/)

When citing, please refer to the published version. 


\title{
Synthesis and antibacterial activity of Iron-Hexacyanocobaltate nanoparticles
}

\author{
Michela Ciabocco, ${ }^{\mathrm{a}}$ Patrizia Cancemi, ${ }^{\mathrm{b}}$ Maria Luisa Saladino, ${ }^{\mathrm{b}, \mathrm{c}}$ Eugenio Caponetti, ${ }^{\mathrm{b}, \mathrm{c}}$ Rosa Alduina, ${ }^{\mathrm{b}}$ Mario Berrettoni ${ }^{*}$ \\ a Department of Industrial Chemistry “Toso Montanari”, University of Bologna, UOS Campus di Rimini, Via dei Mille \\ 39, 47921-Rimini, Italy
}

E-mail: mario.berrettoni@unibo.it

b Department of Biological, Chemical and Pharmaceutical Sciences and Technologies (STEBICEF), University of Palermo, Viale delle Scienze bd.16 and 17, 90128-Palermo, Italy

${ }^{\mathrm{c}}$ Polo CGA-ATeN-Center, University of Palermo, Via F. Marini 14, 90128-Palermo, Italy

\begin{abstract}
The paper deals with the synthesis and characterization of Iron-Hexacyanocobaltate (FeHCC) and its antibacterial properties. The nanoparticles were prepared by a facile co-precipitation technique. Crystal structure, particle morphology and elemental composition were determined using X-ray Powder Diffraction (XRD), X-ray fluorescence spectroscopy (XRF), Transmission Electron Microscopy (TEM) and Infrared Spectroscopy (IR). The antibacterial activity of the FeHCC nanoparticles was tested against Escherichia coli and Staphylococcus aureus as models for Gram-negative and Gram-positive bacteria, respectively, by bacterial counting method and microscopic visualization (TEM, FEG-SEM and fluorescence microscopy). The results showed that the FeHCC nanoparticles bind to the bacterial cells, inhibit bacterial growth in a dose- and time-dependent manner, inducing a loss of the membrane potential, the production of reactive oxygen species and the release of macromolecules (nucleic acids and proteins) in the extracellular environment. To the best of our knowledge, this is the first study reporting the antimicrobial effects of Metal-Hexacyanometallates suggesting practical uses of these materials in different areas, such as self-cleaning surfaces or food packaging.
\end{abstract}

Keywords: Metal-Hexacyanoferrates - Iron-Hexacyanocobaltate • Antibacterial activity - Escherichia coli • Staphylococcus aureus

\section{Introduction}

Microorganisms are present everywhere in the world and the ability to control their growth and diffusion is of extreme importance in food and drink to avoid infectious diseases [1-3], in healthcare to avoid disease outbreaks or in cultural heritages to reduce biodeterioration processes [4]. In the last years the emergence of multi drug resistant strains occurred [5]. Hence, there is a growing need to find novel, safe, efficient and economical compounds [6-8] as an alternative to antibiotics for eliminating the spread of bacteria especially in foods or food processing environments. A potential approach to control the microbial contamination in food preparation and on food surfaces is the use of nanomaterials.

Antimicrobial nanocomposite systems are extremely interesting due to the high surface area to volume ratio. It follows from this that nanomaterials are more efficient, since they are able to attach more copies of microbial assemblage and cells [9]. Antimicrobial nanoparticles synthesized and tested for applications in packaging and food storage boxes include silver oxide [10], zinc oxide [11], magnesium oxide nanoparticle [12], and nisin particles produced by microbial fermentation $[13,14]$.

Titanium dioxide is one of the most studied materials in the field of antibacterial applications, anyway its antibacterial activity is efficient only upon irradiation by ultraviolet (UV) light at levels that could provoke severe injure to human 
cells. In the $\mathrm{TiO}_{2}$ nanocomposites, biocidal efficiencies depend on their light absorbance, therefore they exhibit no antimicrobial effect in dark conditions.

In this contest, Metal-Hexacyanometallates (MHCMs) represent an important class of inorganic compounds because of their tunable particle size [15], unique structure, and physicochemical characteristics [16, 17]. MHCMs are solid compounds of mixed valence presenting a face centered cubic ( $f c c)$ unit cell; the best known MHCM is "Prussian Blue", $\mathrm{Fe}_{4}\left[\mathrm{Fe}(\mathrm{CN})_{6}\right]_{3}$. PB analogs can be described (or referred) as a the "soluble" and the "insoluble" form (these terms were assigned historically according to their intrinsic property of forming colloidal solutions and are not referred to the solubility of PB analogues, basically the insoluble form lacks one-fourth of the $\mathrm{B}(\mathrm{CN})_{6}{ }^{3-}$ units, which are replaced by coordinated and non-coordinated water molecules, anyway PB analogs are insoluble in water.

Except for the Metal-Hexacyanoferrates precursor, potassium ferricyanide, MHCMs have never been investigated in the field of antibacterial applications. As reported by Bagramyan et al., potassium ferricyanide is strongly able to inhibit the E. coli growth and survival under anaerobic fermentative conditions [18].

Among the MHCMs compounds, Iron-Hexacyanocobaltate (FeHCC) has not been widely studied in literature; it is reported in papers focusing on Cs sorption probed by Mössbauer spectroscopy technique [19] and its removal in waste solutions through a process involving the precipitation of cesium [20]. The redox activity is likely to come from high spin iron atoms in FeHCC. The electrochemistry of Iron-Hexacyanocobaltate nanoparticles was poorly investigated but it is known that the redox activity of high spin iron centre $\mathrm{Fe}^{2+} / \mathrm{Fe}^{3+}$ occurs [21, 22].

It is worth underlining the FeHCC elevate stability even in different $\mathrm{pH}[23,24]$ and in high humidity conditions, as FeHCC is not soluble in water, avoiding solubilization problems.

To the best of our knowledge, no data are available on the antibacterial efficiency of Iron-Hexacyanocobaltate nanoparticles. Therefore, this study is aimed at reporting the fabrication of Iron-Hexacyanocobaltate by a facile coprecipitation method and offering supportive evidences to indicate that this compound can inhibit both the Gram-negative E. coli and the Gram-positive S.aureus.

\section{Materials and Methods}

\subsection{Chemicals}

$\mathrm{FeCl}_{2}$ and $\mathrm{K}_{3} \mathrm{Co}(\mathrm{CN})_{6}$ chemicals used in this work were reagent grade and were purchased from Sigma-Aldrich. Housedistilled water was further purified with Barnstead NANO Pure II system and was used throughout this work. All experiments were carried out at room temperature and in air, except the dehydration of the sample carried on in oven at $70^{\circ} \mathrm{C}$.

\subsubsection{Chemical synthesis}

Iron-Hexacyanocobaltate (FeHCC) was prepared as described in literature by Berrettoni et. al [16]. Briefly, IronHexacyanocobaltate nanoparticles were synthesized by a facile co-precipitation method adding $0.05 \mathrm{M}$ water solution of the precursor $\mathrm{FeCl}_{2}$ drop wise to an equivalent amount of $\mathrm{K}_{3}\left[\mathrm{Co}(\mathrm{CN})_{6}\right]$ and stirring at room temperature. When the solutions of both the precursors were in contact, a pale yellow colloidal solution, characteristic of FeHCC compound, was obtained. To improve the polymerization, the solution was allowed to stand for a night to enable the deposition of the product. Subsequently, the sample was carefully washed with deionized water to remove the unreacted salts and centrifuged to separate the solid product. Finally, the precipitate was dried at $70^{\circ} \mathrm{C}$.

\subsection{FeHCC characterization}




\subsubsection{X-ray diffraction (XRD)}

XRD measurements were performed on a Rigaku Mo $\mathrm{K}_{\mathrm{a}} \mathrm{X}$-ray source equipped with a Huber goniometer. Cell parameter, $a$, referred to the cubic structure, was calculated as reported by Holland et al. [25] by the unit cell program.

\subsubsection{Transmission electron microscopy (TEM)}

TEM experiments were performed on a high resolution transmission electron microscope (HR-TEM) JEOL JEM-2100 operating at $200 \mathrm{kV}$. In order to perform the analysis, a small drop of the dispersion resulting by mixing the FeHCC powder with isopropanol was deposited on a 300-mesh nickel grid, "holey carbon-coated". After challenge with FeHCC of $E$. coli cells, TEM analysis was performed on the red precipitate (suspended in absolute ethanol).

\subsubsection{Fourier Transform Infrared Spectroscopy (FT/IR)}

FT-IR (Fourier transform infrared spectrometer) spectra were recorded with a Jasco FT/IR-4600 PLUS spectrometer working in transmission mode. 32 scans were typically taken between $4000 \mathrm{~cm}^{-1}$ and $500 \mathrm{~cm}^{-1}$ with a resolution of $1 \mathrm{~cm}^{-}$ 1. Powder spectra were obtained by using $\mathrm{KBr}$ pellets, containing $1 \%$ w/w of FeHCC sample.

Pellets were produced by compressing with 5 ton for $30 \mathrm{~s}$ the powders in a stainless steel mold of $13 \mathrm{~mm}$ in diameter; no pressure effects have been observed by using a manually operated hydraulic press (Specac Ltd., Orpington Kent, UK).

\subsection{Determination of the antibacterial activity}

E. coli K12, S. aureus ATCC25923 and K. rhizophila ATCC9341 were used in this study and were maintained as described elsewhere [26, 27]. E. coli ATCC25922 was used for $\beta$-galactosidase assay.

E. coli and S. aureus are facultative anaerobic microorganisms that can live both in the presence and in the absence of oxygen. . rhizophila is an obligate aerobic environmental microorganism and it was used as a control of anaerobic conditions of growth.

To evaluate the antibacterial effect of KHCF and FeHCC on bacterial survival, bacteria were grown aerobically at $37^{\circ} \mathrm{C}$ in a Luria Bertani (LB) broth (10 g/L tryptone, $10 \mathrm{~g} / \mathrm{L} \mathrm{NaCl}, 5 \mathrm{~g} / \mathrm{L}$ Yeast extract, $\mathrm{pH}$ 7.2). After overnight incubation, 1:100 inoculum was prepared in salt medium, $\mathrm{SM}\left(46 \mathrm{mM} \mathrm{K}_{2} \mathrm{HPO}_{4}, 23 \mathrm{mM} \mathrm{KH}_{2} \mathrm{PO}_{4}, 0.4 \mathrm{mM} \mathrm{MgSO}_{4}, 8 \mathrm{mM}\left(\mathrm{NH}_{4}\right)_{2} \mathrm{SO}_{4}\right.$, $8 \mu \mathrm{M} \mathrm{FeSO}_{4}, 22 \mathrm{mM}$ glucose, $\mathrm{pH}$ 7.4) or in LB medium. Bacteria were grown anaerobically in stationary capped tubes filled entirely with growth medium $(30 \mathrm{~mL})$ or aerobically in vigorously shaken tubes in a medium-tube volume of 1:10 $(3 \mathrm{~mL})$.

$\mathrm{KHCF}$ and FeHCC were added at different concentrations, as indicated in the figure legends. The terminology is conserved for analogy with solutions, anyway it is worth noting that suspensions were used throughout this work.

The bacterial survival was determined by the colony counting method. Serial dilutions per each sample were prepared in liquid growth medium and spread across the surface of a LB agar plate. After overnight incubation at $37^{\circ} \mathrm{C}$, the number of colony forming units (CFU) was counted and $\mathrm{CFU} / \mathrm{mL}$ was deduced, considering the number of CFU/volume plated $(\mathrm{mL}) \mathrm{X}$ dilution factor used. The percentage of bacterial survival was determined considering the CFU at the time of the inoculum at $100 \%(\mathrm{t}=0 \mathrm{~h})$. Each experiment was performed at least in triplicate.

Total bacterial growth was monitored using a Spark ${ }^{\mathrm{TM}} 10 \mathrm{M}$ multimode microplate reader measuring the absorbance of the cultures at $600 \mathrm{~nm}$ that is an indirect way to measure bacterial growth. Since FeHCC adsorbs, its absorbance was subtracted to the absorbance of each sample. The experiment was performed in triplicate. 
Kirby Bauer method, as described by Lo Grasso et al. [28], was used to assess antibacterial activity of the compounds in solid medium; briefly, a mixture of FeHCC was prepared and directly spotted on a LB agar plate containing an overlay of E. coli and K. rhizophila. Antibacterial activity was measured as the diameter of the inhibition halo formed around the spot. The experiment was performed in triplicate.

\subsubsection{Dual staining for assessment of loss of membrane integrity}

E. coli and S. aureus cultures were grown in 24 well culture plates and incubated with the selected compounds in anaerobic and aerobic conditions. Aliquots of $100 \mu \mathrm{L}$ were transferred into Eppendorf tubes, washed twice with phosphate buffer saline (PBS) and incubated with $1 \mu \mathrm{L}$ of an Acridine Orange $(100 \mu \mathrm{g} / \mathrm{mL})$-Ethidium Bromide $(100 \mu \mathrm{g} / \mathrm{mL}) \mathrm{mixture}(1: 1$, v/v). Cells were immediately observed under a fluorescent microscopy (Carl Zeiss) with excitation (488 nm) and emission $(550 \mathrm{~nm})$ at $630 \mathrm{X}$ magnification.

\subsubsection{Intracellular reactive oxygen species (ROS) measurement}

Intracellular ROS levels were measured by using 2',7'-dichlorodihydrofluorescein diacetate (DCFH-DA) and dihydroethidium (DHE) assays. DCFH-DA and DHE are widely used probes to measure intracellular generation of $\mathrm{H}_{2} \mathrm{O}_{2}$ and other oxidants and $\mathrm{O}_{2}^{-}$, respectively. Bacterial cells were grown in LB medium overnight in presence of increasing concentrations of FeHCC. At the end $0.1 \mathrm{~mL}$ samples were incubated with $50 \mu \mathrm{M}$ DCFH-DA or $10 \mu \mathrm{M}$ DHE for $30 \mathrm{~min}$ at room temperature in the dark. Then the medium was replaced with PBS and the fluorescence intensity was analyzed by spectrofluorimeter with an excitation of $488 \mathrm{~nm}$ and emission wavelength of $525 \mathrm{~nm}$ for DCFH-DA and an excitation of $540 \mathrm{~nm}$ and emission wavelength of $590 \mathrm{~nm}$ for DHE. Data normalization was performed with parallel OD 600 measurements. Experiments were carried out in triplicate and error bars were evaluated.

\subsection{Evaluation of morphology by Field Emission Gun-Scanning Electron Microscopy (FEG-SEM)}

FEG-SEM investigations was performed using a FEI versa 3D microscope. After incubation overnight at $37^{\circ} \mathrm{C}$ in $\mathrm{LB}$ medium with increasing concentrations of FeHCC, the cells were harvested, rinsed with sterile PBS three times and fixed in $2.5 \%$ formaldehyde at room temperature for $20 \mathrm{~min}$, followed by three washes with PBS. The samples were dehydrated through a concentration series of ethanol $(30 \%, 50 \%, 70 \%, 90 \%, 100 \%$ for $15 \mathrm{~min}$ each). Then, one drop of the samples suspended in ethanol was put on a holey-carbon coated copper grid of 300 mesh and left to air to dry. Micrographs were obtained using an accelerating voltage of $10 \mathrm{kV}$.

\subsection{Determination of membrane potential $(\Delta \psi)$}

The membrane potential $(\Delta \psi)$ was determined using the JC-1 green/red dye-based assay. JC-1 (Sigma Aldrich) was prepared as a stock of $5 \mathrm{mg} / \mathrm{mL}$ in dimethyl sulfoxide (DMSO) and stored at $-20^{\circ} \mathrm{C}$ until use. A working solution (20 $\mu \mathrm{g} / \mathrm{mL}$ ) of the dye was prepared in $1 \mathrm{~mL}$ of a permeabilization buffer containing $10 \mathrm{mM}$ TrisHCl, $\mathrm{pH} 7.5,1 \mathrm{mM}$ EDTA, and $10 \mathrm{mM}$ glucose. Overnight cultures were diluted 1:100 in fresh LB medium and increasing concentrations of FeHCC were added. A $1 \mathrm{~mL}$ sample of each culture was harvested during exponential phase $\left(\mathrm{OD}_{600}=0.8\right)$, and resuspended in 1 $\mathrm{mL}$ working solution of $\mathrm{JC}-1$, and subsequently incubated at $30^{\circ} \mathrm{C}$ in the dark. After incubation, cells were harvested and resuspended in PBS and the fluorescent intensities were recorded by spectrofluorimeter at $530 \mathrm{~nm}$ (green emission) and $590 \mathrm{~nm}$ (red emission). Membrane depolarization is indicated by an increase in the green/red fluorescence intensity ratio. 
The potential-sensitive color shift is due to concentration-dependent formation of red fluorescent JC-aggregates. Data were normalized with total bacterial count. Experiments were carried out in triplicate and error bars were evaluated.

\subsection{Evaluation of cell leakage}

The membrane leakage was evaluated by extraction of proteins and nucleic acids released extracellularly by the cells. Briefly, after the treatments, $1 \mathrm{~mL}$ samples were harvested by centrifugation and the supernatant was transferred into a new Eppendorf tube. Total proteins were precipitated with $4 \mathrm{~V}$ of cold acetone for $24 \mathrm{~h}$ at $-20^{\circ} \mathrm{C}$ and nucleic acids were precipitated with $0.3 \mathrm{M}$ Sodium acetate and $2 \mathrm{~V}$ of $100 \%$ ethanol at $-20^{\circ} \mathrm{C}$ for $2 \mathrm{~h}$. Proteins and nucleic acids were collected by centrifugation. After washes with acetone $/ \mathrm{H}_{2} \mathrm{O}(4: 1 \mathrm{v} / \mathrm{v})$ or $70 \%$ ethanol, proteins and nucleic acids were resuspended in Laemli buffer and $\mathrm{H}_{2} \mathrm{O}$, respectively. In addition, intracellular proteins and nucleic acids were extracted. Briefly, cells recovered from $1 \mathrm{~mL}$ samples after centrifugation were lysed by boiling for 10 minutes; total cell extracts were used directly for SDS-PAGE analysis as previously described [29,30] and for DNA agarose gel electrophoresis using a 1\% agarose gel at $100 \mathrm{~V}$ for $30 \mathrm{~min}$ in $1 \times$ TAE buffer as described in Caracappa et al. [31]. For $\beta$-Galactosidase assay activity, E. coli ATCC25922 cells were grown overnight at $37{ }^{\circ} \mathrm{C}$ in LB broth and diluted 100 -fold into the same medium containing increasing concentrations of FeHCC. After growth to mid-exponential phase $\left(\mathrm{OD}_{600}=0.4\right)$ cultures were assayed for $\beta$-galactosidase activity. Briefly, expression of $\beta$-Galactosidase was induced incubating the cells in presence of $1 \mathrm{mM}$ IPTG for $2 \mathrm{~h}$ at $37^{\circ} \mathrm{C}$. After this time, cells were centrifugated and medium transferred into new tubes and 1 $\mathrm{mg} / \mathrm{mL}$ of o-nitrophenyl- $\beta$-D-galactoside (ONPG) was added. This compound is colorless and make the medium yellow if hydrolyzed into galactose and ortho-nitrophenol by $\beta$-galactosidase. Ortho-nitrophenol amount was measured at 420 $\mathrm{nm}$. The data were normalized using total bacterial count. Experiments were carried out in triplicate and error bars were evaluated.

\section{Results and Discussion}

\subsection{Characterization of FeHCC}

XRD patterns for the FeHCC investigated compound, shown in Supplementary Information (Fig. S1), confirms the success of the synthesis [22] and are consistent with the typical $f c c$ lattice of MHCMs.

Indeed, FeHCC nanoparticles obtained matched the standard MHCMs cubic structure, having lattice cell parameter of $a$ $=10.10 \AA$ (calculated by the unit cell program [25]), very close to the cell parameter of many other MHMCs.

A close inspection of the reflection peaks indicates a presence of the rhombohedral distortion, split of the peaks.

Results obtained by Fourier Transform Infrared Spectroscopy characterization can be seen in Fig. 1, providing useful information on the structure of the studied compounds [32].

In Iron-Hexacyanocobaltate, cyanide at its $\mathrm{C}$ end behaves as a very strong ligand resulting in low spin electronic configuration for the metal in the molecular block $\left[\mathrm{Co}(\mathrm{CN})_{6}\right]$. At the $\mathrm{N}$ end it forms more ionic bond and therefore the outer metal is usually found in a high spin state [33]. IR spectrum of Iron Hexacyanocobaltate, shown in Fig. 1, is composed of absorption bands from vibrations related to the octahedral $\mathrm{Fe}\left[\mathrm{Co}(\mathrm{CN})_{6}\right]$ structural unit, $\delta(\mathrm{CoCN}), \mathrm{v}(\mathrm{CN})$, $\mathrm{v}(\mathrm{CoC})$, and those from the crystal water, $\delta(\mathrm{HOH})$ and $\mathrm{v}\left(\mathrm{H}_{2} \mathrm{O}\right)$, in complete agreement with the data in literature [22,34]. The stretching vibration related to the coordinated water in MHMCs is usually observed as sharp bands around $3550 \mathrm{~cm}^{-}$

${ }^{1}$ but strongly overlapped with the broad absorption band due to that motion from the hydrogen bonded water. In IronHexacyanocobaltates, the $\mathrm{v}(\mathrm{CoC})$ vibration usually falls below $400 \mathrm{~cm}^{-1}$ and with the IR spectrophotometer used it can not be observed. The inset in Fig. 1 shows the $2100-2300 \mathrm{~cm}^{-1}$ frequencies range relative to the $\mathrm{CN}$ stretching frequencies. 
It is worth underlining that the $\mathrm{v}(\mathrm{CN})$ frequency is quite high for the FeHCC compound $\left(2181 \mathrm{~cm}^{-1}\right)$, reflecting the Co$\mathrm{CN}-\mathrm{Fe}$ chain, probably due to a strong Fe(III)-N metal-ligand interaction, and the presence of a small second peak at 2127 $\mathrm{cm}^{-1}$, probably due to the residual iron atoms in the reduced oxidation state. In FeHCC compounds a mix of Fe(II) and $\mathrm{Fe}(\mathrm{III})$ in different ratios always occurs, as reported by Mössbauer spectroscopic data (not shown).

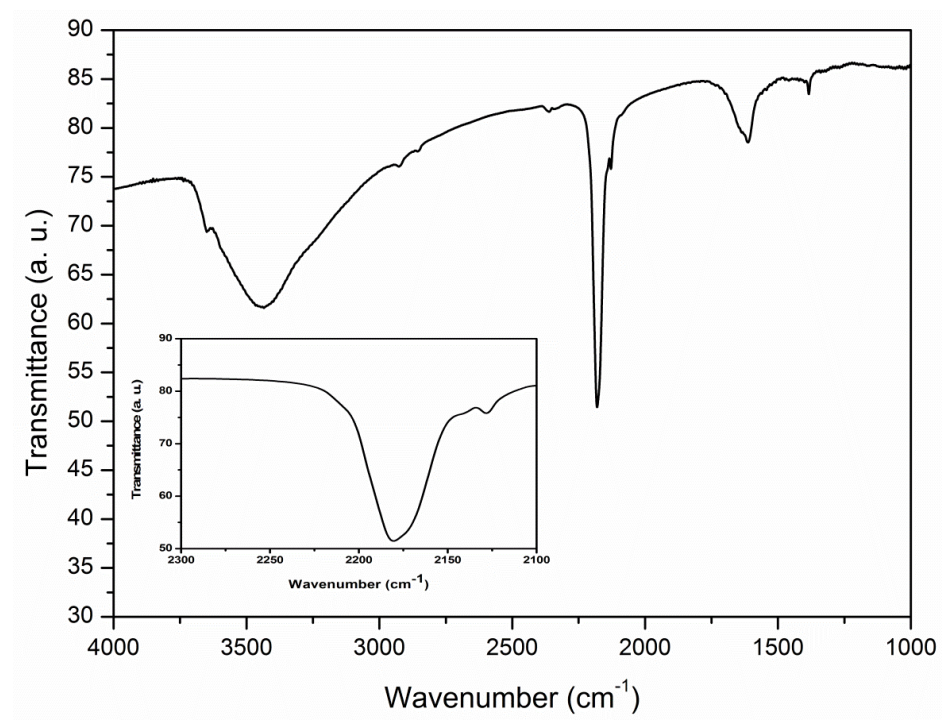

Fig1. IR spectra of the FeHCC powder in the region from 4000 to $1000 \mathrm{~cm}^{-1}$. The inset shows the frequencies from 2000 to $2300 \mathrm{~cm}^{-1}$ relative to the $\mathrm{CN}$ group stretching.

The FeHCC powder was also characterized by TEM. Figure 2 shows TEM micrographs of FeHCC at different magnifications, confirming the typical cubic aggregate of FeHCC with an average size of $50 \div 100 \mathrm{~nm}$.

MHMC particles cannot be obtained with the same identical size, because the aging of the colloidal preparation, obtaining by pouring out together the two precursors at the same moment, is a parameter that plays a key role on the final product. It can cause a slight increase in the particles size, and in particular, the expansion and the structural changes of surface properties with drying temperature is attributed to the faster evacuation of water molecules that contributes to the creation of supplementary pores and to the conversion of iron from the ferrous form to the ferric one. It is worth highlighting that this phenomenon represents an added value for these compounds because their reactivity is significantly improved and the increase of the size can be considered negligible for these applications. These nano-structure particles may provide a suitable surface to adsorb active components, such as bacteria. 

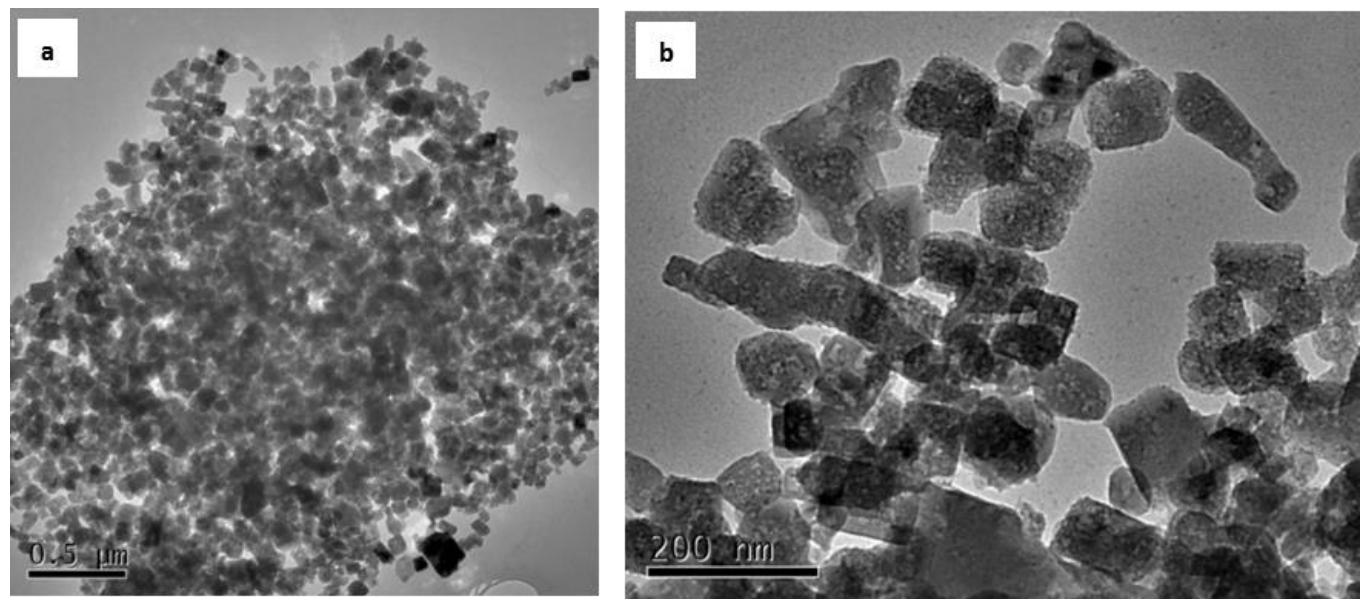

Fig2. TEM micrographs of the FeHCC cubic aggregates at different magnifications.

\subsection{Antibacterial activity of FeHCC against $E$. coli}

Antibacterial activities of FeHCC and KHCF were compared by growing E. coli in salt medium under anaerobic conditions and adding increasing concentrations $(0.5,1$ and $2 \mathrm{mM})$ of the two compounds. Bacterial survival was determined by the colony counting method. As shown in Fig. 3, treatment of E. coli with both FeHCC and KHCF reduced bacterial survival in a time and dose-dependent manner.

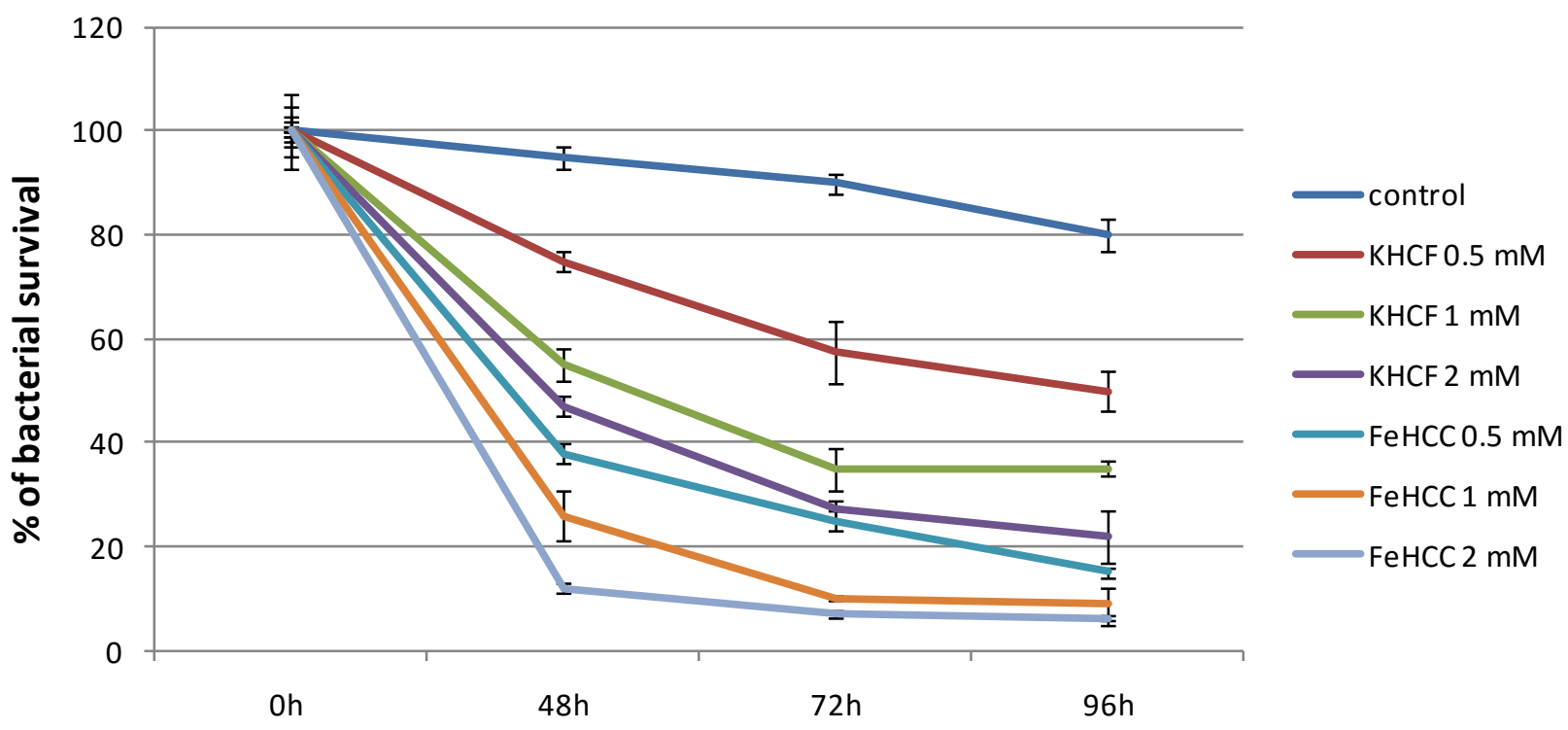

Fig3. Percentage of bacterial survival under anaerobic fermentative conditions in presence of $0.5,1$ and $2 \mathrm{mM}$ of KHCF and FeHCC. The control indicates the survival of E. coli in the salt medium (no addition). The values are expressed as percentage of bacterial survival relative to E. coli at the time of inoculation (no addition). Data are average from triplicate experiments. Error bars represent standard deviations of triplicate incubations.

FeHCC showed a higher antibacterial activity compared to KHCF (Fig. 3): indeed after 48h the survival percentages in presence of increased concentrations of KHCF and FeHCC were of 75, 55, 47\% and 37, 26 and 11\%, respectively. The antibacterial activity of FeHCC in aerobic conditions was also evaluated by colony counting method. In aerobiosis (Fig. 
4 A), $1 \mathrm{mM}$ FeHCC produced a slight decrease in bacterial growth (82\% compared to the control). The low antibacterial activity of FeHCC on bacterial growth could be dependent upon the fact that in aerobiosis a much higher growth occurs, thus a larger amount of FeHCC is needed to inhibit bacterial growth.

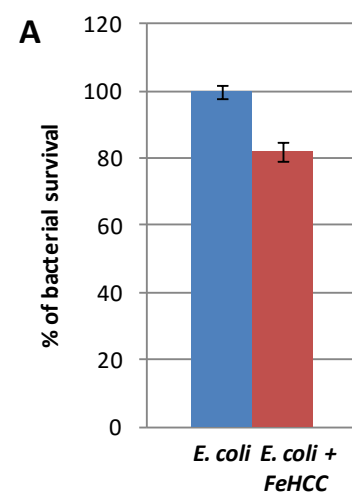

B1

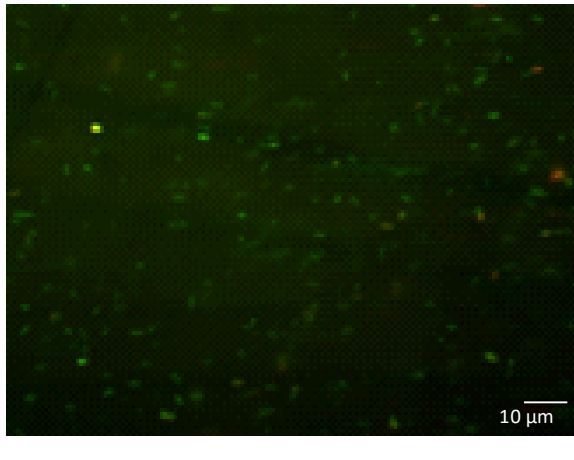

B2

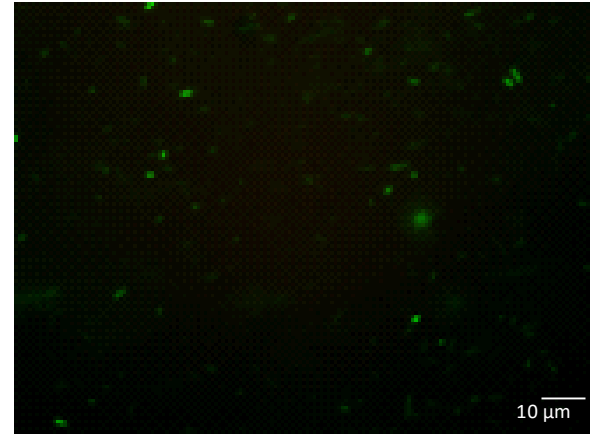

C

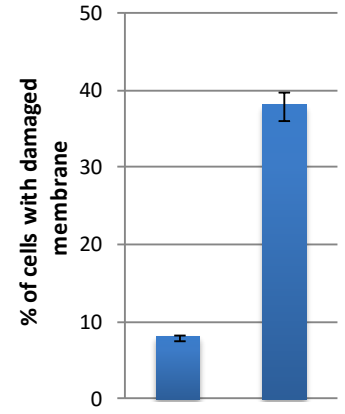

D

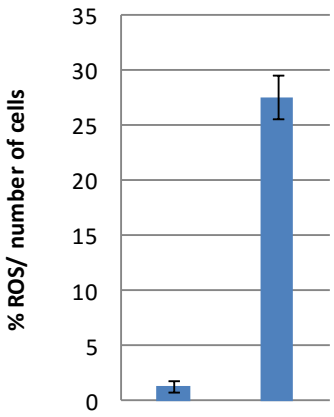

E
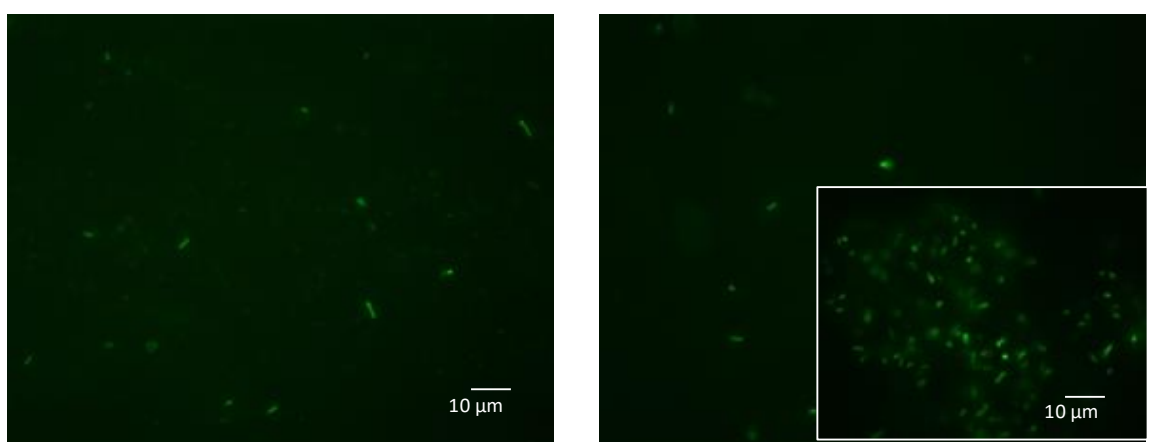

Fig4. Effect of $1 \mathrm{mM}$ FeHCC on E. coli growth in salt medium in aerobiosis.

A) Percentage of total bacteria after treatment with $1 \mathrm{mM}$ of FeHCC. The values are expressed as percentage relative to E. coli growth in SM medium (no addition).

B) Fluorescence micrographs of control (B1) and treated (B2) cells after dual staining with AO/EB.

C) Percentage of cells with damaged membranes, evaluated by counting at least 100 cells in three different fields.

D) Quantification of ROS production with DCFH-DA.

E) Fluorescence micrographs at $680 \mathrm{X}$ magnification. Insert represents the field in which aggregation zones were visible.

Dual staining with acridine orange and ethidium bromide of the two cultures was performed and the bacteria were visualized under fluorescence microscope. Acridine orange is a neutral dye that permeates passively through the cells with intact membranes. Ethidium bromide, a charged dye, is taken up only if the cells have lost membrane integrity. Cells with intact membranes appear uniformly green, whereas cells with damaged membranes also incorporate ethidium bromide and therefore stain orange. 
Interestingly, as reported in Fig. 4B1 and 4B2, control cells stained only with acridine orange, while in the FeHCC-treated sample the number of cells with damaged membranes increased (Fig. 4C). In addition, the production of reactive oxygen species (ROS) was evaluated after FeHCC treatment by using DCFH-DA.The quantitative results (Fig. 4D) and qualitative observation under microscope, especially in some bacterial aggregates (Fig. 4E1 and 4E2), confirmed the induction of ROS production by FeHCC in E. coli cells, which in turn could be responsible of the bacterial membrane damage.

After challenge, a red precipitate in the inoculum tubes was formed; thus, we investigated whether structural changes to FeHCC had occurred.

TEM analysis allows direct visualization of morphological changes of $E$. coli due to the presence of FeHCC nanoparticles and/or changes in the shape of FeHCC nanoparticles after incubation with bacteria. FeHCC nanoparticles were clearly distinct and visible from the cellular matrix because of the high electron density of iron.

It is worth noting that no modification of the shape of FeHCC nanoparticles was revealed by TEM analysis after incubation with bacteria confirming that FeHCC physical-chemical properties were maintained. The stability of IronHexacyanocobaltate compounds was confirmed also by IR spectra and most of all by electrochemical techniques (in particular cyclic voltammetry) recorded after FeHCC incubation with bacteria, showing FeHCC characteristic bands and reversible redox centers at Fe site, respectively.

TEM analysis showed cells surrounded by nanoparticles (Fig. 5A-B-C), cells with wrinkles (indicated by red arrows in Fig. 5B-C), and totally leaked cells (Fig. 5D), but no nanoparticles inside the cells were detected, at least in the used conditions. It seems like that $E$. coli cells work as nucleation center for nanoparticles aggregation. 

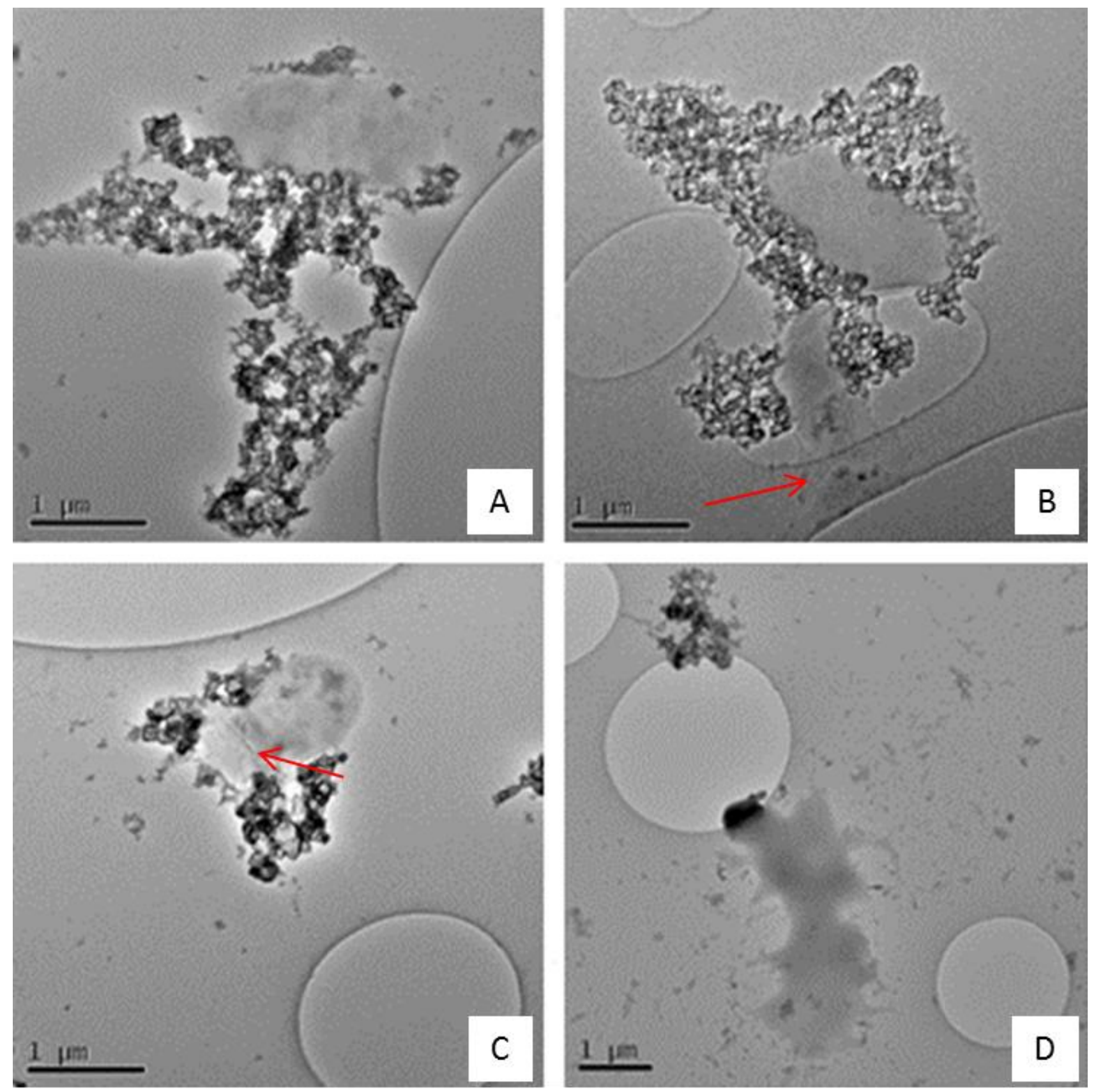

Fig5. TEM micrographs of $E$. coli after $48 \mathrm{~h}$ challenge with FeHCC. Red arrows indicate wrinkles in $E$. coli surface.

\subsection{Antibacterial activity of FeHCC against Gram-positive and Gram-negative bacteria in a rich medium}

FeHCC antibacterial activity was evaluated also against the Gram-positive bacteria, such as K. rhizophila and S. aureus. As shown in Supplementary Information (Fig. S2), $30 \mathrm{mM} \mathrm{FeHCC} \mathrm{in} \mathrm{presence} \mathrm{of} \mathrm{oxygen} \mathrm{were} \mathrm{able} \mathrm{to} \mathrm{inhibit} \mathrm{the} \mathrm{growth}$ of $K$. rhizophila with a more extent than E. coli. This encouraging result indicated that the compound is more active against Gram-positive than Gram-negative microorganisms; the latter contains an additional outer membrane that is likely to reduce or to delay the action of FeHCC.

Afterwards, the Minimal Inhibitory Concentration (MIC) was evaluated against E. coli and S. aureus using the serial dilution method in both aerobic and anaerobic conditions for $24 \mathrm{~h}$ and the colony counting method. As shown in Fig. 6 , FeHCC was able to reduce the bacterial load of both E. coli and S. aureus in a dose-dependent manner. 
A

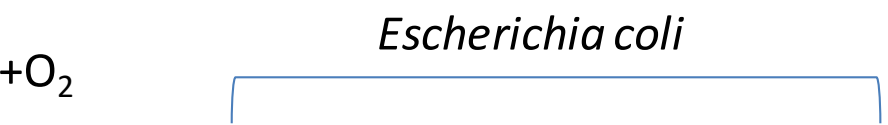

Staphylococcus aureus

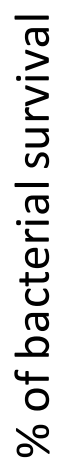

$+\mathrm{FeHCC}$

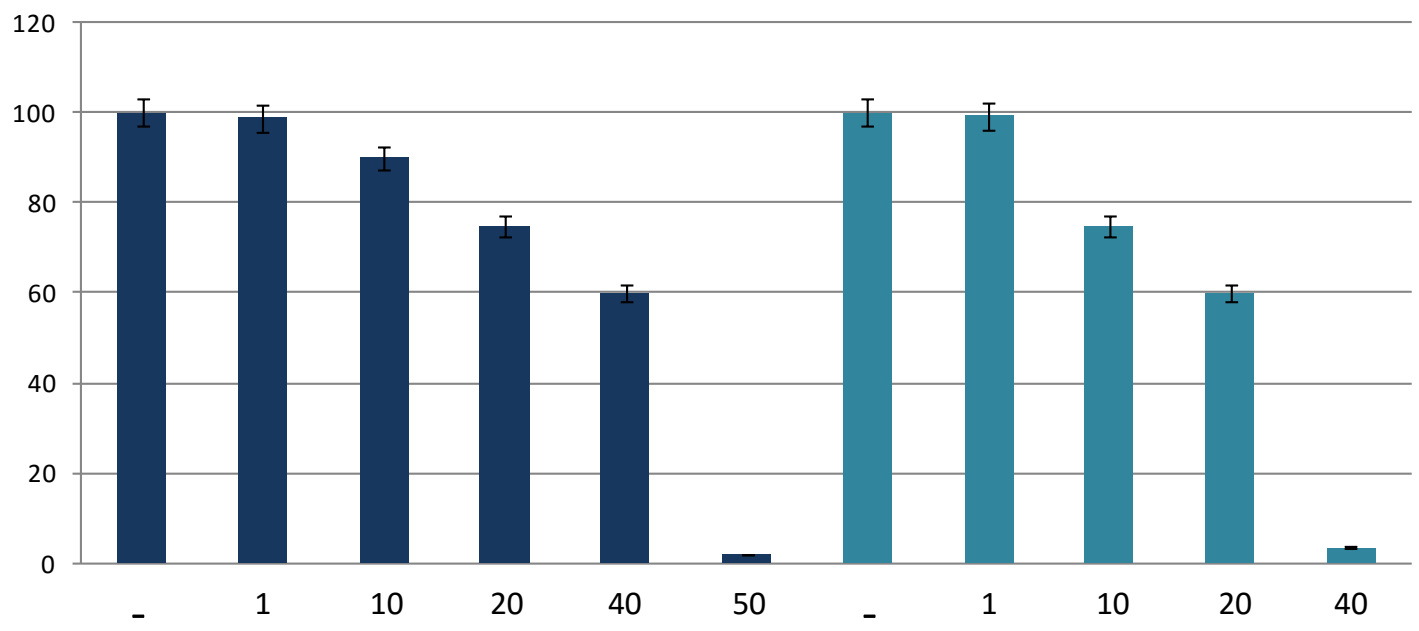

(mM)

B

$-\mathrm{O}_{2}$

Escherichia coli

Staphylococcus aureus

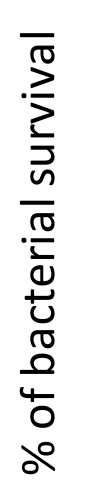

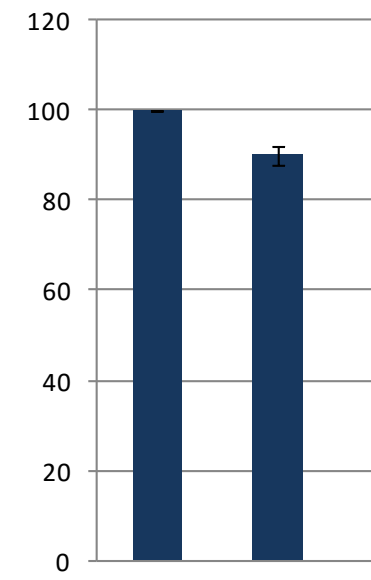

$+\mathrm{FeHCC}$

1

10

20

50

40

$(\mathrm{mM})$

Fig6. The percentage of bacterial survival under aerobic (A) and anaerobic (B) conditions in presence of 1, 10, 20, 40 and $50 \mathrm{mM}$ of FeHCC. The values are expressed as percentage of bacterial survival relative to E. coli and S. aureus growth, indicated by -. Data are average from triplicate experiments. Error bars represent standard deviations of triplicate incubations.

In this medium and in presence of oxygen, $1 \mathrm{mM}$ of the compound is not effective on bacterial growth. $10 \mathrm{mM}$ of nanoparticles reduced the bacterial load of S. aureus to $75 \%$ and of E. coli only to $90 \%$. The addition of $20 \mathrm{mM}$ of FeHCC reduced to $60 \%$ and $75 \%$ the growth of $S$. aureus and E. coli, respectively. $40 \mathrm{mM}$ of FeHCC was enough to inhibit almost the totality of $S$. aureus, while the bacterial vital cells of E. coli were still the $60 \%$ in respect to the control. $50 \mathrm{mM}$ of FeHCC were sufficient to reduce the bacterial load of $E$. coli to $2 \%$. This result confirmed that Gram-positive bacteria are more susceptible than E. coli to FeHCC. Similarly, in anaerobiosis we got the same effect, a dose-dependent inhibition 
of $S$. aureus growth with $40 \mathrm{mM}$ able to inhibit the growth of almost all the bacteria (99.5\%), differently $50 \mathrm{mM}$ of FeHCC were not enough to get the same result with E. coli (15\% of cells are still viable).

\subsection{Antibacterial mechanism of FeHCC}

So far, our results showed that FeHCC nanoparticles are more active against $S$. aureus than E. coli, cannot enter inside the cells and they keep their structure after challenge; on the other hand, we found that cells can be bound by the nanoparticles, and that above a threshold of nanoparticles bounded, cell leakage probably occurs.

To investigate the antibacterial mechanism of FeHCC nanoparticles, we performed deeper analyses after $4 \mathrm{~h}$ of treatment with $0,1,10$ and $20 \mathrm{mM}$ of FeHCC for $S$. aureus and 0, 1, 10, 20 and $40 \mathrm{mM}$ for E. coli. Firstly, the integrity of the bacterial membranes was evaluated by AO/EB staining. As shown in Fig. 7, the untreated cells are alive with intact membranes and display only green fluorescence. In contrast, the treated cells show also the red fluorescence, confirming the membrane damage. At $40 \mathrm{mM}$ no $S$. aureus cells were present, while at $50 \mathrm{mM}$ only a few E. coli cells were detected, confirming the results of bacterial survival shown in Fig. 6.

\section{S. aureus}

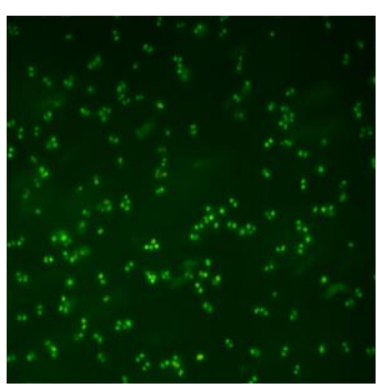

$+\mathrm{FeHCC}$

(mM)

\section{E. coli}

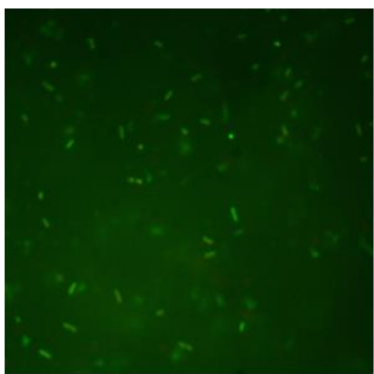

$+\mathrm{FeHCC}$

(mM)

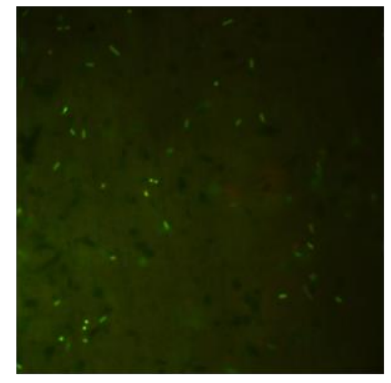

20

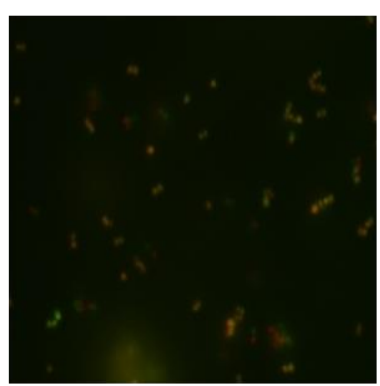

20

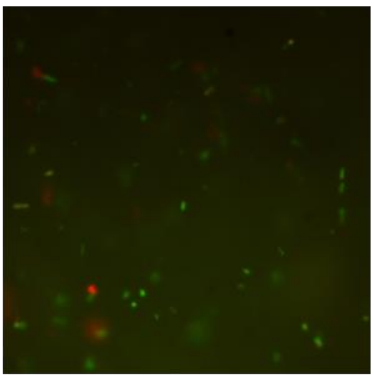

40

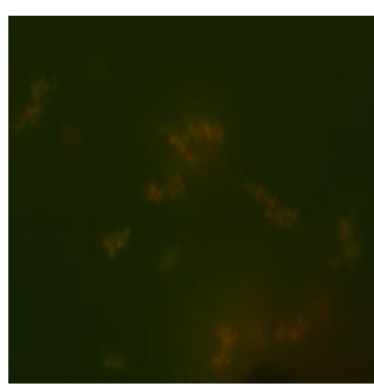

40

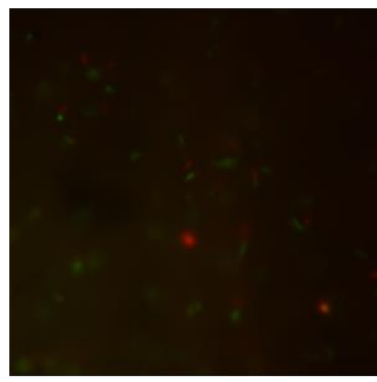

50

Fig7. Fluorescence micrographs of $S$. aureus and E. coli cells after dual staining with acridine orange and ethidium bromide. Cells were incubated in aerobic conditions for $24 \mathrm{~h}$ with increasing concentrations of FeHCC and, after dual staining, visualized under fluorescence microscope at 680X magnification.

The morphological changes and membrane integrity of E. coli and S. aureus after $4 \mathrm{~h}$ of treatment were evaluated via FEG-SEM. The analyses (Fig. 8) revealed the binding between FeHCC nanoparticles and bacterial cells, with the latter 
showing their cell membranes wrinkled, damaged and in some cases open, while the untreated cells appeared smooth, rod-shaped with intact cell membranes (Fig. 8A and B).

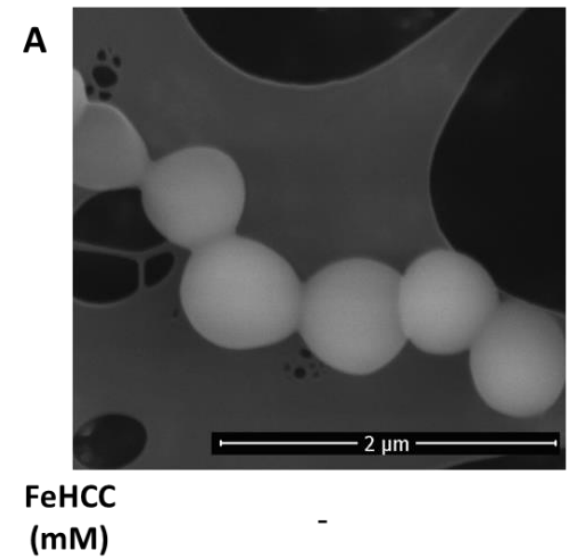

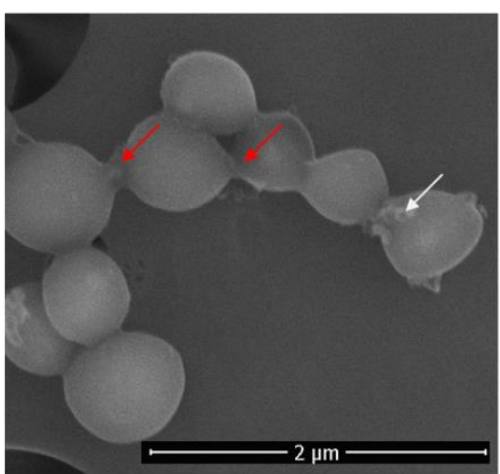

10

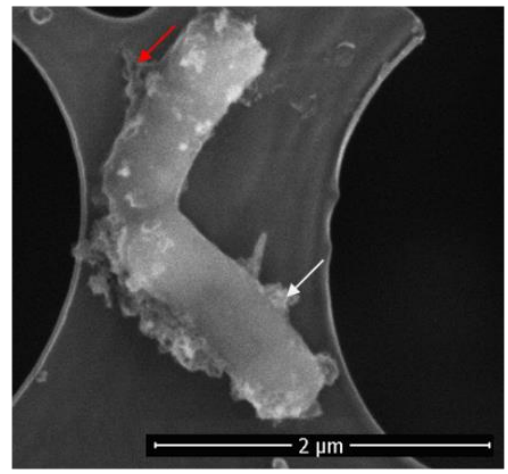

20

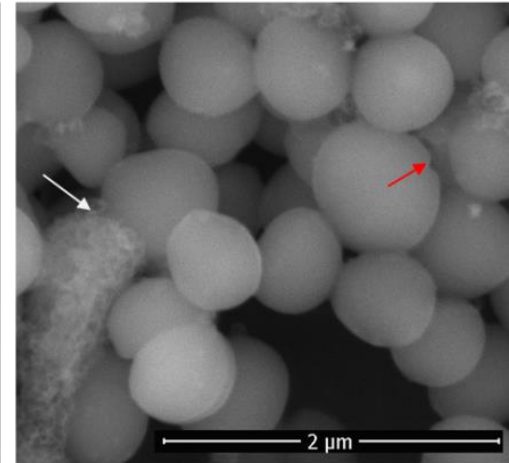

20

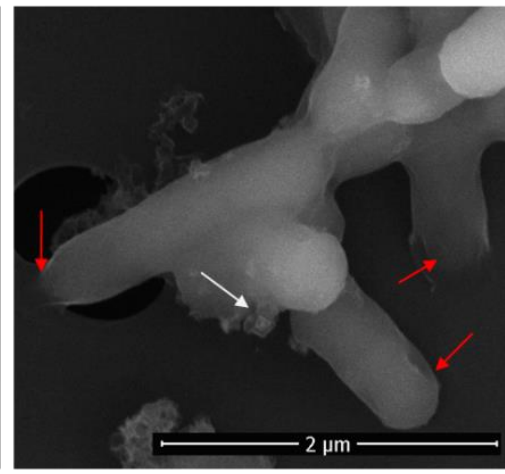

40

Fig8. Scanning electron micrographs of S. aureus (A) and E. coli (B) with different concentrations of FeHCC for 4h. The red and white arrows indicate the membrane defects and the FeHCC nanoparticles, respectively.

To test whether the nanoparticles impaired electron transport chain, the membrane potential was evaluated following the FeHCC treatment, by using the JC-1 green/red dye-based assay. JC-1 is a membrane-permeating dye which in its monomeric form emits a green fluorescence $(530 \mathrm{~nm})$ when excited. Following membrane depolarization JC-1 form aggregates whose fluorescence emission shifts from green to red $(590 \mathrm{~nm})$. Consequently, the membrane potential variation can be expressed as a ratio of red/green fluorescence intensities. Treatment of E. coli and S. aureus with different concentrations of FeHCC (Fig. 9) exhibited a significant loss of membrane potential, mainly for E. coli cells, compared to the untreated cells, as indicated by its higher green/red ratio. This result does not exclude that also the engulfment of the membrane could be an additional effect of the nanoparticles. 


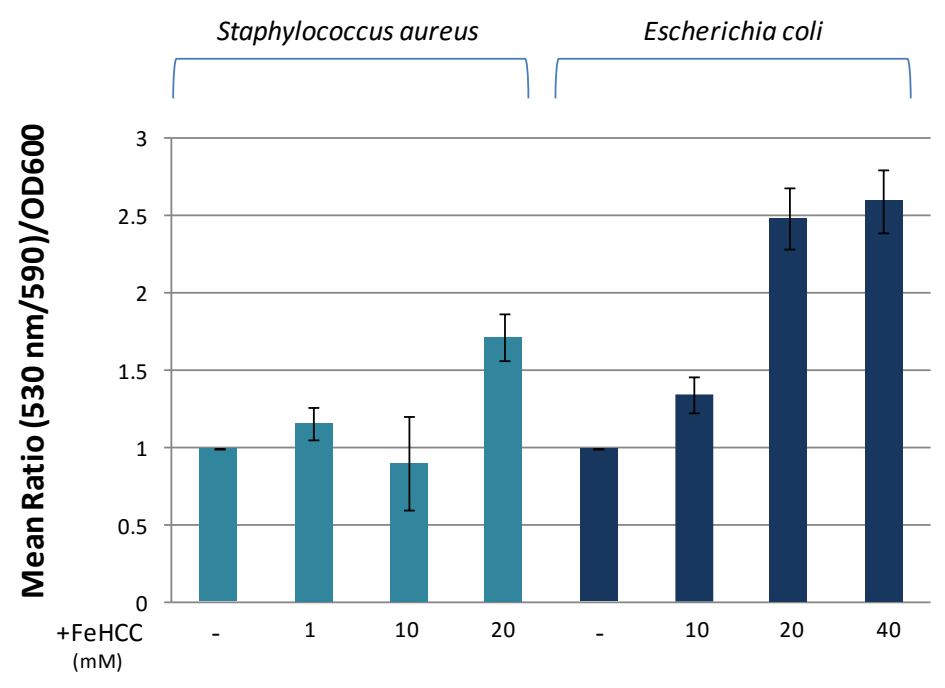

Fig9. Assessment of the membrane potential using JC-1 green/red dye-based assay. An increase in the green/red ratio indicates a decrease in the membrane potential.

Since oxidative stress is one of the proposed antibacterial mechanisms of metal nanoparticles [35], the involvement of oxidative stress in antibacterial activity was examined through the measurement of generic intracellular reactive oxygen species (ROS) production and in particular, $\mathrm{H}_{2} \mathrm{O}_{2}$ by DCFH-DA assay and anion superoxides by DHE assay. As shown in Fig. 10, FeHCC treatment triggers a concentration-dependent increase of $\mathrm{H}_{2} \mathrm{O}_{2}$ production for both $S$. aureus and E. coli, while it has a slight effect on anionic superoxides production.
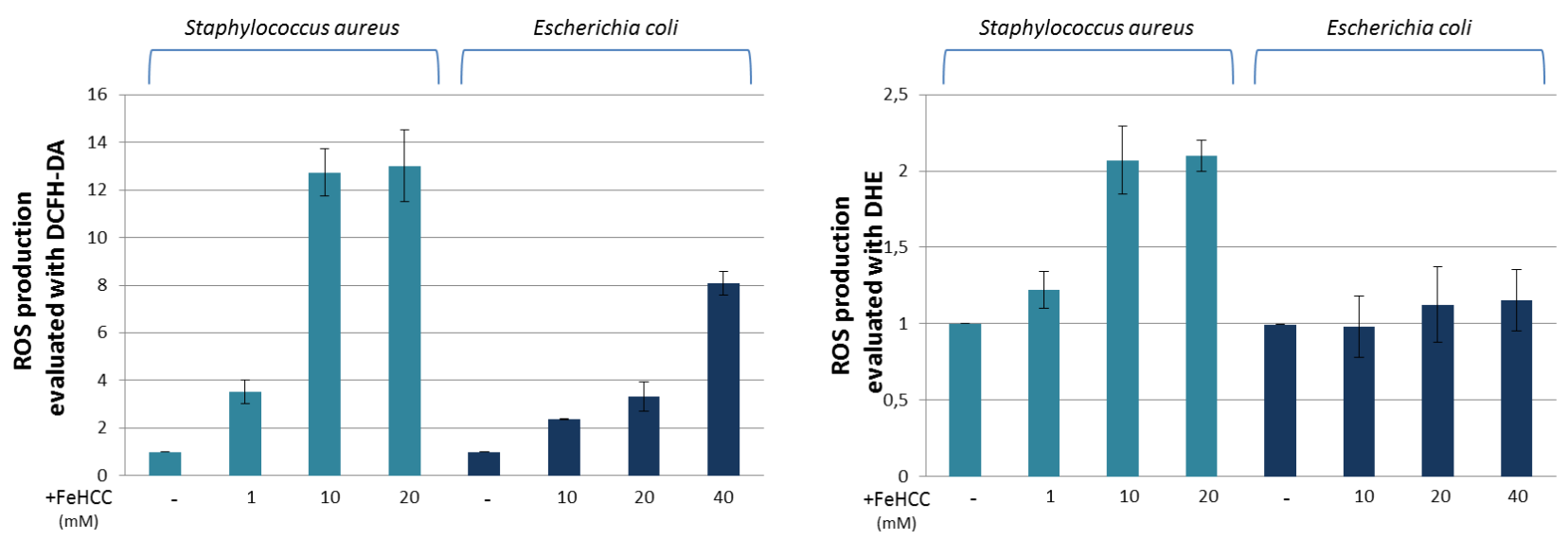

Fig10. Quantification of ROS production. $\mathrm{H}_{2} \mathrm{O}_{2}$ was revealed by DCFH-DA and $\mathrm{O}_{2}^{-}$by DHE. Data were normalized with $\mathrm{OD}_{600}$ measurements.

This implied that ROS production together with membrane damage could be responsible for cell death. Thus, we investigated if nanoparticles binding and oxidative stress cause leakage of cytoplasmic contents as DNA and proteins. Cell leakage was investigated evaluating DNA and protein content in both the bacteria spent medium and cell lysates, after incubation with increasing concentration of the FeHCC for $2 \mathrm{~h}$. The SDS-PAGE electrophoresis revealed a dosedependent increase of protein content in the spent medium of the treated bacteria with a concomitant decrease of intracellular proteins (Fig. 11A). The same trend was observed for DNA content (Fig. 11B). The bacterial membrane 
permeability of $E$. coli was also investigated by testing $\beta$-D-galactosidase activity in the spent medium, where the enzyme could be released only if cells were leaked. As shown in Fig. 11C the $\beta$-D-galactosidase activity increased after exposure to FeHCC.

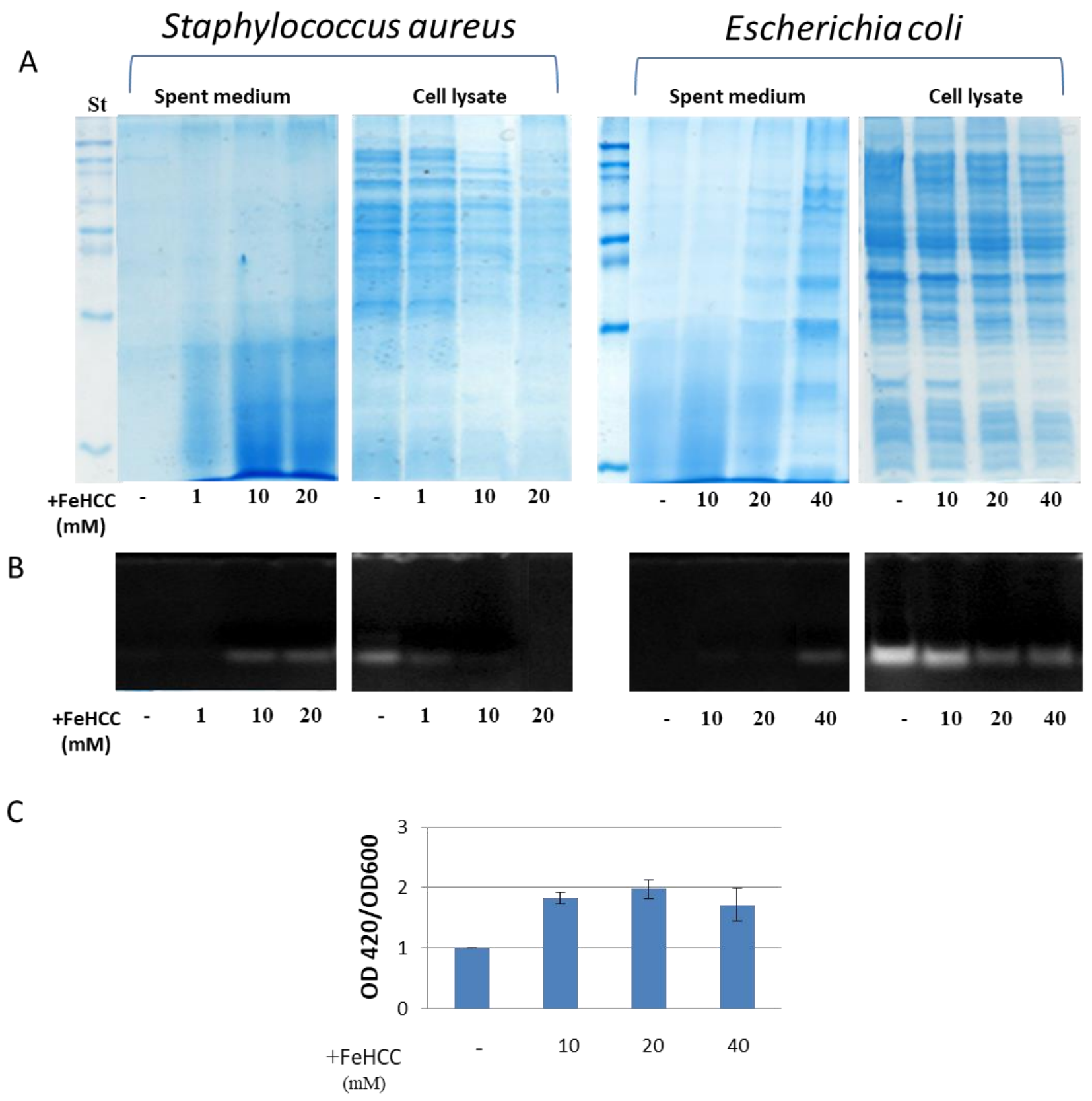

Fig11. Measurement of total proteins and nucleic acids, released in the spent medium and extracted from the E. coli and S. aureus cells after treatment with increasing concentrations of FeHCC. Cell leakage was indicated by SDS-PAGE electrophoresis (A), agarose gel electrophoresis (B) and evaluation of $\beta$-galactosidase activity in the spent medium by using ONPG assay. (C)

Concerning metal nanoparticles as antimicrobial agents [36], growth inhibition and cellular death are likely the result of a combination of different mechanisms, derived from adhesion of the nanoparticles to the cell membrane, release of ions 
and internalization of both nanoparticles and ions. Inside the cells, this leads to dysfunction of cellular processes at different levels [37-40].

It is worth noting that the structure of FeHCC nanoparticles makes these materials different from common antimicrobial agents. Indeed, FeHCC surface contains - $\mathrm{CN}$ functional groups and $\mathrm{Fe}^{2+}$ and $\mathrm{Fe}^{3+}$ atoms, marked by high and low electron densities, making the compound both negatively and positively charged in different external areas. TEM analysis showed a high density of nanoparticles adsorbed on the cell surface; we surmise through the high density of cationic charges present on the surface nanoparticles bind to negatively charged microbial membranes by electrostatic interaction. Subsequently, we suppose that the nanoparticles could disturb the bacterial metabolism [41], due to FeHCC redox activity of high spin iron centre $\mathrm{Fe}^{2+} / \mathrm{Fe}^{3+}$ well note in literature [42], and its subsequent oxidation capability.

Summarizing, we suppose that the antibacterial activity of FeHCC, through both electrostatic and electrochemical synergistic mechanisms, affects different bacterial processes, such as the membrane potential, the membrane permeability and the oxidative stress leading to the cell death [43].

\section{Conclusions}

The synthesis and characterization of Iron-Hexacyanocobaltate (FeHCC) nanoparticles and its antibacterial properties were deeply investigated. The particles were prepared by a facile co-precipitation technique. The physicochemical characterization was carried out by X-ray Powder Diffraction (XRD), X-ray fluorescence spectroscopy (XRF), Transmission Electron Microscopy (TEM) and Infrared Spectroscopy (IR) confirming the success of the synthesis. XRD pattern of FeHCC is consistent with the typical $f c c$ lattice of MHMC compounds and FeHCC cell parameter, $a$, referred to the cubic structure, is $10.10 \AA$, very close to the cell parameter of many other MHMCs.

This nano-structure provides a suitable surface to adsorb active components, such as bacteria, displaying antimicrobial activity against the Gram-positive $S$. aureus and the Gram-negative E. coli bacterial strains.

Based on our experimental results, we can propose a model in which the binding of the FeHCC nanoparticles to the envelope of bacteria leads to the membrane destabilization, as revealed by SEM and loss of membrane potential, increased permeability, as demonstrated by the increase of macromolecules in the extracellular medium, and oxidative stress, as verified by the formation of reactive oxygen species.

The above findings are obviously correlated to the Metal-hexacyanometallates electrochemical properties, well known in literature and hence it is worth considering their redox features in thinking about how oxidative stress could occur and be detected inside the bacteria.

As supported by IR spectra and electrochemical techniques respectively, Fe atoms in the oxidized state are present on FeHCC lattice surfaces and redox activity at high spin iron centre $\mathrm{Fe}^{2+} / \mathrm{Fe}^{3+}$ occurs.

Hence, after challenge with bacteria strains, $\mathrm{Fe}^{3+}$ could reduce to $\mathrm{Fe}^{2+}$ oxidizing bacteria membrane surfaces and leading to dysfunction of cellular processes. Also, structures inside the cell, such as enzymes and DNA, could be affected.

Furthermore, these findings allows us to explain the chemical nature of the red precipitate formed in the inoculum tubes after challenge. In the redox process of Iron-Hexacyanocobaltate, and in particular upon the reduction process, the insertion of an alkali metal (in this case $\mathrm{Na}^{+}$) takes place in order to maintain the electro-neutrality of the compound. The reaction is rapid and no structure disruption occurs, but a red precipitate is observed likely due to the formation of $\mathrm{NaFeHCC}$.

In conclusion, we cannot infer if a simple aggregation or specific ionic interaction leads to the adhesion between the nanoparticles and the cells; and we cannot exclude that the nanoparticles could have multiple effects simultaneously. 
Although the precise mechanism by which FeHCC exerts the bactericidal effect remains unclear, in consideration that FeHCC nanoparticles are not toxic towards higher organisms, as verified by the blood agar test (data not shown), the investigation of the antimicrobial properties of this compound could be interesting in order to develop new technological applications for antimicrobial packaging, for instance for the use of these compounds in plastic materials.

\section{Acknowledgements}

This work is part of the project "Development and Application of Innovative Materials and processes for the diagnosis and restoration of Cultural Heritage - DELIAS" - PON03PE_00214_2 (Programma Operativo Nazionale Ricerca e Competitività 2007-2013).

TEM experimental data were provided by Polo Centro Grandi Apparecchiature - ATeN Center-Università di Palermo funded by P.O.R. Sicilia 2000-2006, Misura 3.15 Azione C Quota Regionale. FEG-SEM experimental data were provided by the ATeN-Center of University of Palermo, Laboratorio di preparazione di biomateriali.

\section{References}

[1] Zhao X, Zhao F, Wang J, Zhong N (2017) RSC Adv 7:36670-36683.

[2] D'Andrea A, Martinez YZ, Alduina R, Monteverde V, Molina CF, Vitale M (2012) Mem Inst Oswaldo Cruz 107:85-88.

[3] Vitale M, Scatassa ML, Cardamone C, Oliveri G, Piraino C, Alduina R, Napoli C (2015) Foodborne Pathog Dis 12:21-23.

[4] Randazzo L, Montana G, Alduina R, Quatrini P, Tsantini E, Salemi B (2015) J Cult Herit 16:838-847.

[5] Charnley M, Textor M, Acikgoz C (2011) React Funct Polym 71:329-334.

[6] Rubino S, Busà R, Attanzio A, Alduina R, Di Stefano V, Girasolo MA, Orecchio S, Tesoriere L (2017) Bioorg Med Chem 25:2378-2386.

[7] Cancemi P, Buttacavoli M, D'Anna F, Feo S, Fontana RM, Noto R, Sutera A, Vitale P, Gallo G. (2017) New J of Chem 41:3574-3585.

[8] Dresler C, Saladino ML, Demirbag C, Caponetti E, Chillura Martino DF, Alduina R. (2017) Int Biodeterior Biodegradation 125:150-156.

[9] Luo PG, Stutzenberger FJ (2008) Adv Appl Microbiol 63:145-181.

[10] Sondi I, Salopek-Sondi B (2004) J Colloid Interf Sci 275:177-182.

[11] Li J, Tan L, Liu X, Cui Z, Yang X, Yeung KWK, Chu PK, Wu S (2017) ACS Nano 11:11250-11263.

[12] Jones N, Ray B, Koodali RT, Manna AC (2008) FEMS Microbiol Lett 279:71-76.

[13] Gadang VP, Hettiarachchy NS, Johnson MG, Owens C (2008) J Food Sci. 73:389-394.

[14] Amna T, Hassan MS, Yousef A, Mishra A, Barakat NAM, Khil MS, Yong Kim H (2013) Food Bioprocess Technol 6:988-996.

[15] Ciabocco M, Berrettoni M, Zamponi S, Cox JA (2016) J Solid State Electrochem 20:1323-1329.

[16] Berrettoni M, Ciabocco M, Fantauzzi M, Giorgetti M, Rossi A, Caponetti E (2015) RSC Adv 5:35435-5447.

[17] Ciabocco M, Berrettoni M, Giorgetti M, Sougrati MT, Louvain N, Stievano L (2016) New J Chem 40:1040610411.

[18] Bagramyan K, Galstyan A, Trchounian A (2000) Bioelectroch 51:151-156.

[19] Rykov AI, Wang J, Zhang T, Nomura K (2013) Hyperfine Interact 218:53-58.

[20] Beheir SG, Benyamin K, Mekhail FM (1998) J Radioanal Nucl Chem 232:147-150. 
[21] Widmann A, Kahlert H, Petrovic-Prelevic I, Wulff H, Yakhmi JV, Bagkar N, Scholz F (2002) Inorg Chem. 41:5706-5715.

[22] Ciabocco M, Berrettoni M, Chillura Martino DF, Giorgetti M (2014) Solid State Ionics 259:53-58.

[23] Garjonyte R, Malinauskas A (1998) Sensors and Actuators B 46:236-241.

[24] Ciabocco M, Berrettoni M, Zamponi S, Cox JA, Marini S (2013) J Solid State Electrochem 17:2445-2452.

[25] Holland TJB, Redfern SAT (1997) Mineral Mag 61:65-77.

[26] Giardina A, Alduina R, Gottardi E, Di Caro V, Süssmuth RD, Puglia AM (2010) Microb Cell Fact 9:44-54.

[27] Vitale M, Gaglio S, Galluzzo P, Cascone G, Piraino C, Di Marco Lo Presti V, Alduina R. (2017) Foodborne Pathog Dis. Dec 20. doi: 10.1089/fpd.2017.2338.

[28] Lo Grasso L, Maffioli S., Sosio M, Bibb M, Puglia AM, Alduina R (2015) J Bacteriol 197:2536-2544.

[29] Musso R, Di Cara G, Albanese NN, Marabeti MR, Cancemi P, Martini D, Orsini E, Giordano C, Pucci-Minafra I. (2013) J Proteomics 90:115-125.

[30] Cancemi P, Di Cara G, Albanese NN, Costantini F, Marabeti MR, Musso R, Riili I, Lupo C, Roz E, PucciMinafra I. (2012) Proteomics Clin Appl. 6:364-373.

[31] Caracappa S, Pisciotta A, Persichetti MF, Caracappa G, Alduina R, Arculeo, M. (2016) Can J Zool 94:379-383.

[32] Nakamoto K. Infrared and Raman Spectra of Inorganic and Coordination Compounds, John-Wiley and Sons, New York, Chichester, Brisbane, Toronto, Singapore, 1986, p. 484.

[33] Sharpe AG, Maitlis P, Stone FAG, West R. The Chemistry of Cyano Complexes of the Transition Metals, Academic Press, New York, 1976.

[34] Roque J, Reguera E, Balmaseda J, Rodríguez-Hernández J, Reguera L, del Castillo LF (2007) Micropor Mesopor Mat 103:57-71.

[35] Buttacavoli M, Albanese NN, Di Cara G, Alduina R, Faleri C, Gallo M, Pizzolanti G, Gallo G, Feo S, Baldi F, Cancemi P. (2017) Oncotarget.

[36] Lemire JA, Harrison JJ, Turner RJ (2013) Nature rev 11:371-384.

[37] Lin S, Liu X, Tan L, Cui Z, Yang X, Yeung KWK, Pan H, Wu S (2017) ACS Appl Mater Interfaces 9:19248-19257.

[38] Xie X, Mao C, Liu X, Zhang Y, Cui Z, Yang X, Yeung KWK, Pan H, Chu PK, Wu S (2017) ACS Appl Mater Interfaces 9:26417-26428.

[39] Mao C, Xiang Y, Liu X, Cui Z, Yang X, Yeung KWK, Pan H, Wang X, Chu PK, Wu S (2017) ACS Nano 11:9010-9021.

[40] Xiang Y, Li J, Liu X, Cui Z, Yang X, Yeung KWK, Pan H, Wu S (2017) Mater Sci Eng C 79:629-637.

[41] Auffan M, Achouak W, Rose J, Roncato MA, Chanéac C, Waite DT, Masion A, Woicik JC, Wiesner MR, Bottero JY (2008) Environ Sci Technol 42:6730-6735.

[42] Widmann A, Kahlert H, Petrovic-Prelevic I, Wulff H, Yakhmi JV, Bagkar N, Scholz F (2002) Inorg Chem 41:5706-5715.

[43] Kügler R, Bouloussa O, Rondelez F (2005) Microbiology 151:1341-1348. 